\title{
ПОНЯТЬ УКРАИНУ. СОСТОЯНИЕ РОССИЙСКОЙ УКРАИНИСТИКИ
}

\begin{abstract}
Аннотация. Весной этого года вылли в свет два номера журнала «Россия в глобальной политике», полностью посвящённые Украине. Высоко оценивая сам этот факт, автор пытается составить общее представление о том, насколько адекватно российские экспертьл, чьи статьи опубликованы в этих номерах, представляют происходящее там, и как эти представления соотносятся с оценками украинских и зарубежных экспертов. В статье выдвигается и обосновывается гипотеза о том, что неудачи российской политики наУкраине обусловлены, в том числе, состоянием украинских исследований в России. Автор приходит к выводу, что попыткам урегулирования кризиса в российско-украинских отнотениях должно предшествовать переосмысление имеющихся представлений об Украине и о том, в чём состоит действительный начиональный интерес России в отношениях с ней.
\end{abstract}

Ключевые слова: Россия, Украина, российско-украинские отночения, украинский кризис, Европейский союз, Украинская республика, урегулирование.

Чему учат российско-украинские отношения? Тому, что на вызовы необходимо реагировать адекватно. К сожалению, российско-украинские отношения не таковы. Они сегодня являются тем внешним фактором, который во многом определяет темпы модернизации в обеих странах. А она происходит с недопустимым отставанием, обе страны - одна раньше, другая позже - рискуют оказаться «в хвосте» регионального и глобального процессов.

Подумалось об этом в связи с выходом в свет двух номеров журнала «Россия в глобальной политике», целиком посвящённых Украине ${ }^{1}$. Сразу скажем, это - неординарное и радостное событие в российской украинистике, пройти мимо которого было бы большой ошибкой.

«Этот номер журнала совсем необычный, - пишет главный редактор журнала Фёдор Лукьянов, - он сдвоенный... и посвящён одной теме - Украине» (Часть 1:5). Он также полагает, что в теме «Украина» для России «сосредоточилась едва ли не вся международная повестка последних десятилетий» (Часть 2:171). Действительно, значительная, если не бо́льшая, часть проблем российской внешней политики не может быть сегодня решена без учёта «украинского фактора».

Можно было бы порадоваться этому, но что-то мешает. Мешает скорее всего ощущение сублимации - того, что российские авторы говорят применительно к Украине о том, чего не могут и не хотят сказать о своей стране.

Неадекватная реакция на происходящее на Украине - старая российская болезнь. Алексей Миллер утверждает, что всё происходившее и происходящее на Украине описывается в двух оптиках. «Одна из них - это телеологическая оптика естественности и безальтернативности процесса, который, подобно траве, пробивающейся сквозь асфальт, неизбежно преодолевает все препятствия, создаваемые антиукраинской политикой империи. Другая оптика...

(C) Мироненко Виктор Иванович - кандидат исторических наук, ведущий научный сотрудник, руководитель Центра украинских исследований ИЕ РАН. Aдрес: 125009, Россия, Москва, ул. Моховая, д. 11, стр. 3.E-mail: victor@mironenko.org.

DOI: http://dx.doi.org/10.15211/vestnikieran6201814

${ }^{1}$ Россия в глобальной политике, части 1 и 2, 2018, № 2-3, март-июнь. 
оценивает этот процесс как цепь трагических, противоестественных случайностей и плод интриги разнообразных антирусских сил» 1.

Похоже, что российские политики и эксперты с какого-то момента (примерно с 2004 г.) рассматривают Украину исключительно через вторую из описанных «оптик». Поэтому событие, о котором идёт речь, я воспринимаю как попытку последовать совету российского историка «посмотреть на этот процесс иначе - как на процесс закономерный, но не предопределённый» 2 . Только в такой «оптике» появляется шанс понять Украину. И ещё одно справедливое замечание делает А. Миллер: «русификация Украины» в XIX в.это «не только история успеха борьбы украинских националистов, но и история неудачи их противников» ${ }^{3}$. Перечисляя причины, по которым российско-украинские отношения пришли в их нынешнее плачевное состояние, Ф. Лукьянов называет (пусть и последней в перечне) провал российской политики. «С начала 1990-х гг. она... не добилась ни одной из долгосрочных целей - ни геополитических, ни экономических, ни культурно-гуманитарных» $(2: 171)$. А далее - ещё резче и определённее: «Постсоветский опыт отношений с Украиной можно рассматривать разве что в качестве негативного примера - как не надо было поступать» (2:179).

Поэтому основными достоинствами рассматриваемого компендиума я считаю:

- сам факт постановки проблемы в отличной от распространённого в официальном и комплиментарном по отношению к нему экспертном и медийном дискурсах;

- попытку рассмотреть проблему с нескольких точек зрения (российской, зарубежной и украинской) и в разных ракурсах (историческом, экономическом, политическом);

- сопоставление вариантов развития событий в «бермудском» политическом треугольнике: ЕС - Россия - Украина.

Рассматриваемая сумма текстов даёт объёмное и, в основном, объективное представление об «украинском кризисе» и отношению к нему в России, ЕС и США.

Первая рубрика сдвоенного номера журнала, озаглавленная «Попытка анамнеза» (Часть 1:8-54) задаёт тон дальнейшего освещения и обсуждения проблемы. Из двух текстов, помещённых под этой рубрикой - Алексея Попова (Часть 1:8-34) и Глеба Павловского (Часть 1: 34-54) - следует, что в «анамнезе» нуждается Украина. Но украинская болезнь это очевидно болезнь роста, детская, скажем так, болезнь. Это - во-первых. А, во-вторых, «анамнезов» бывает много. Есть, например, «аллергологический анамнез». Это, попросту говоря, - реакция на ошибки в диагнозе. Так вот, изучая российскую политику в отношении Украины, убеждаешься в том, что «лечение» бывает опаснее самой болезни.

Здесь, правда, нужно оговориться. Если таким был замысел творцов соответствующей политики, он вполне удался. Мы получили и имеем на Украине «реактивный национализм», то есть, национализм, лишённый конкретного политического содержания. Во всяком случае, на Украине до событий весны 2014 г. И, добавим, возможностями его критики, чем многие у нас в России и занимаются, в том числе и в рассматриваемом нами тексте: С. Переверзенцева (Часть 1:66-82, В. Брукнера (Часть 2:124-144) Т. Бордачёва (Часть 2:30-32) А. Фененко (Часть 2:38-40, И. Сафранчука (Часть 2: 44-45).

Вся первая часть рассматриваемого компендиума посвящена историческому анализу. Начинает его Джованни Савино попыткой (не слишком удачной, на наш взгляд, но заслужи-

\footnotetext{
1 Алексей Миллер. Россия и русификация Украины в XIX веке. 2018. URL: http://litopys.narod.ru/vzaimo/ vz12.htm (дата обращения: 12.07.2018 г.).

2 Там же.

${ }^{3}$ Там же.

4 Этого автора трудно отнести к одной из трёх представленных категорий. Судя по имени, он - иностранец, но
} Научно-аналитический вестник ИЕ РАН, 2018, №6 
вающей отдельного тщательного разбора) вписать украинский проект в европейский исторический и актуальный политический контекст ${ }^{1}$. Продолжают тему два историка: упоминавшийся уже Сергей Перевезенцев (Россия) и Георгий Касьянов (Украина). Оба, особенно первый, излагают похожий собственный критический и, к сожалению, не слишком информативный, взгляд на государственное строительство на Украине.

Далее следует статья Андрея Теслиํ․ Он делится наблюдением, имеющим отношение к предложенному нами пониманию «анамнеза». Оно состоит в том, что речь у нас часто идёт не столько об Украине, которая худо бедно, дорогой ценой, но меняется и обрела некую новую форму (нравится она кому-то или нет), а о России, которой ещё предстоит её обрести (см. об этом также в рубрике «Русский мир» (Часть 1:22-167): А. Чеснаков (Часть 1:122-127) Б. Межуев (Часть1:134-136) и др.).

Дискуссию о «Русском мире» продолжают (не менее информативно и интересно) извлечения из статей А. Миллера, А. Сдвижкова, Д. Ширле, А. Котенко и О. Мартынюка. Алексей Миллер «закругляет» её резкой критической констатацией того, что «после 2014 года те, кто не принимает концепции «Русского мира»... утвердились во мнении, что «Русский мир» это концепция аншлюса» (Часть 1:128).

В самом конце следующей рубрики «Неуловимый малоросс. Историческая справка» (Часть 1:105-122) обнаруживаем под грустным названием - «Смерть малоросса» суждение А. Миллера: «понятие «малоросс» как вариант самоидентификации сегодня уже умерло, но умирало оно долго и мучительно - не само по себе. Его вытравливали» (Часть 1:120). Из сказанного не совсем понятно, кто и когда «вытравливал». Читатель, который может не знать о том, что А. Миллер написал, возможно, одну из лучших книг об истории борьбы с «украинством» в Российской империи ${ }^{3}$ и не слишком сведущий в перипетиях «политики коренизации» в СССР может остаться в глубоком неведении относительно самого этнонима «малоросс» и его судьбы (почему оно стало нарицательным).

Вторая часть компендиума открывается рубрикой, озаглавленной «Поле битвы после победы» и посвящена проблемам безопасности. В ней находим статью Андрея Кортунова и беседу с Джереми Шапиро, а также заочную дискуссию, проведённую методом опроса, о том, «каким могло бы быть военно-политическое положение Украины в Европе, например, в 2030 году». Редакционной находкой можно считать то, что в ней объединены были три разных взгляда на проблему: российских, украинских и зарубежных (европейских и американских) экспертов.

А. Кортунов утверждает: «чтобы рассчитывать на большее, на протяжении ближайших нескольких лет все стороны многоуровневого конфликта (Россия, Украина и условный «совокупный Запад») должны изменить не только тактику или даже стратегию, но - и это гораздо сложнее - базовые представления о том, что привело их всех к этому тяжелейшему кризису и что постоянно подпитывает этот кризис» (Часть 2:8). Вполне созвучно этому и утверждение Джереми Шапиро о том, что «независимая, стабильная Украина, имеющая эффектив-ные взаимоотношения с обеими сторонами, не входящая в союзы, которые каждая из сторон считает угрожающими для себя» может и должна быть целью соответствующей политики всех вовлечённых в конфликт сторон. Но реализовать её непросто потому, что «для этого каждая

\footnotetext{
представлен как доцент Института общественных наук РАНХиГС при президенте РФ.

1 Джованни Савино Европеизм или национализм? О национальном строительстве в Европе и Украине // Россия в глобальной политике, март-июнь, часть 1. С. 54-65.

2 Андрей Тесля. Россия без Украины: трансформация большого нарратива. Когда имперское уходит, а национальное не приходит // Россия в глобальной политике, март-июнь, часть 1, 2018. С. 96-105.

3 Миллер А.И. «Украинский вопрос в политике властей и русском общественном мнении (вторая половина XIX в.). - СПб.: Алетейя, $2000-260$ с.
} 
сторона должна быть уверена, что Украину не используют против неё» (Часть 2: 22).

Кстати, поставленные рядом статьи А. Кортунова и Дж. Шапиро - единственный случай в рассматриваемом тексте, когда взгляды российского и зарубежного (американского) экспертов были созвучны. Во всех остальных случаях обнаруживаем противоположную модальность текстов российских, с одной стороны, и иностранных авторов, с другой. Если первые в большинстве случаев ищут «виновных» (и находят их на Украине или «на Западе»), то вторые, почти без исключения, пытаются искать и предлагают решения. Украинские эксперты, возможно в силу того, как осуществлялся их выбор, находятся в этом отношении где-то посередине.

Перспективам развития экономики Украины до 2030 г. посвящён раздел, названный «Украинская экономика: верить в чудо?», представляющий собой изложение материалов круглого стола, организованного редакцией журнала. Экономический обзор завершается текстом, подготовленным Анной Жихаревой и озаглавленным «Прощание с советским газом».

Два последних раздела объединены поиском разрешения российско-украинского конфликта / войны и поделённом на два подраздела с заглавиями «Свет в конце туннеля» (Часть 2:76-124). Здесь, отмеченная выше разнонаправленность анализа проявилась особенно выпукло и ярко.

Сергей Куделя предлагает пять принципов и три сценария урегулирования кризиса (Часть 2:76-90). Винсент Делла Сала (Часть 2:90-100) вслед за премьер-министром Италии Маттео Ренци предложил для выхода из тупика модель урегулирования по типу Альто-Адидже $^{1}$. Иван Крастев (Часть 2:110-116) подтвердил данные ему редакцией оценки и представил один из самых объективных описаний процессов, происходящих в треугольнике «ЕС - Россия - Украина». Тимоти Болтон и Самуэль Чарап дают совершенно адекватное, уникальное по глубине и объективности, во всяком случае, из всех мне известных, описание глобального политического контекста «украинского кризиса» (Часть 2:116-123).

Из объективного, не замутнённого «гибридностью» анализа возникает возможное решение или, по крайней мере, единственно возможное основание для решения «украинского» и всех других восточно-европейских кризисов: «Для России это означает признание, что подход с нулевой суммой к своим соседям оказался крайне затратным, рискованным и контрпродуктивным. Регулярное использование принуждения - будь то политическое, военное или экономическое - оттолкнуло страны, которые при других обстоятельствах могли бы быть вместе с Россией. США и ЕС должны признать, что, несмотря на успехи в Центральной и Восточной Европе, дальнейшее применение методики 1990-х гг. - распространение евроатлантических институтов на восток, к границам России, но не на неё - уже нежизнеспособно» (Часть 2:117-118). На этом фоне статью Владимира Брутера при всём желании трудно назвать находкой редакции. Как и материалы Г. Иоффе и М. Вигнанского, помещённые в последней рубрике «Обмен опытом» (Часть 2:144-159).

Завершает вторую часть и оба номера текст главного редактора журнала Фёдора Лукьянова «Украинский вопрос для будущего России».

Авторское послесловие главного редактора к беспрецедентному и для журнала и для России публичному обсуждению острейшей и важнейшей проблемы всего уходящего постсоветского пространства и Евразии, знаменательно попыткой отказаться от ряда устоявшихся представлений и об Украине, и о российско-украинских отношениях, я бы сказал сменой тональности попыткой посмотреть не только на Украину своими глазами, но и на себя глазами украинцев.

\footnotetext{
${ }^{1}$ Альто-Адидже (итал. Trentino-Alto Adige/ Südtirol, нем. Trentino-Südtirol) - автономная область на севере Италии. Научно-аналитический вестник ИЕ РАН, 2018, №6
} 
И пусть в нём, как и во всём континууме, представленном редакцией, нет попытки с российской или украинской стороны предложить какой-то иной подход к выстраиванию двусторонних отношений в современном европейском и глобальном контекстах (в отличие от иностранцев и, может быть, А. Кортунова (Россия) и Александра Чалого и Леонида Кожары (Украина) констатация ошибочности политики на этом направлении и предложение отказаться от привычки видеть мир и соседей не такими, какие они есть, а какими нам удобно их видеть, большой шаг вперёд или, во всяком случае, подготовка необходимых условий для того, чтобы такой шаг сделать.

Центр украинских исследований Института Европы РАН намерен ещё не однажды обратиться к помещённым в рассмотренном сборнике текстов на страницах Аналитического бюллетеня ИЕ РАН и журнала «Современная Европа» в поиске путей разрешения «украинского кризиса» и возвращения стран Восточной Европы в общеевропейский процесс. Мы выражаем благодарность коллегам из журнала «Россия в глобальной политике» за смелое и результативное в целом обращение к столь горячей и актуальной теме современных международных отношений.

\section{Список литературы}

Россия в глобальной политике, части 1 и 2, 2018, №2-3, март-июнь.

Миллер А., Сдвижков Д., Ширле И. (ред.) «Понятия о России». К исторической семантике имперского периода. М., НЛО, 2012. Т. 2. Р. 392-443.

Алексей Миллер. Россия и русификация Украины в XIX веке. 2018. URL: http://litopys. narod.ru/vzaimo/vz12.htm (дата обращения: 12.07.2018 г.).

\section{References}

Rossiya v globalnoy politike, chasti 1 i 2, 2018, №2-3, mart-iyun.

Miller A., Sdvizhkov D., Shirle I. (red.) «Ponyatiya o Rossii». K istoricheskoy semantike imperskogo perioda. M., NLO, 2012. T. 2. P. 392-443.

Aleksey Miller. Rossiya i rusifikatsiya Ukrainyi v XIX veke. 2018. URL: http://litopys.narod. ru/vzaimo/vz12.htm (12.07.2018).

\section{To understand Ukraine. The State of the Russian Ukrainian Studies}

Author. Victor Mironenko, Candidate of Sciences (History), Head of the Centre of Ukrainian Studies, Institute of Europe, Russian Academy of Sciences. Address: 11-3, Mokhovaya str., Moscow, Russia, 125009. E-mail: victor@mironenko.org.

Abstract. This spring two issues of the journal «Russia in the global politics», totally dedicated to Ukraine were published. Highly appreciating this fact, the author tries to make the general vision how adequately Russian experts, whose articles were published in these issues, represent what is taken place there and how these presentation corresponds with the assessment of Ukrainian and foreign experts. In this article the hypothesis is put forward and proved that failures of Russian politics in Ukraine are caused as well by the state of research of Ukraine in Russia. The author comes to the conclusion that the attempts to regulate the crisis in the Russian-Ukrainian relations should be preceded by thinking over of the present ideas about Ukraine and about what is the real national interest of Russia in the relations with Ukraine.

Key words: Russia, Ukraine, Russian-Ukrainian relations, Ukrainian crisis, European Union, Ukrainian Republic, regulation.

DOI: http://dx.doi.org/10.15211/vestnikieran6201814 